\title{
The effect of zooplankton on the dynamics and molecular composition of carbohydrates during an experimental algal bloom
}

\author{
Theis KRAGH*, Morten SØNDERGAARD and Niels H. BORCH \\ Freshwater Biological Laboratory, University of Copenhagen, 51 Helsingørsgade, DK-3400 Hillerød, Denmark \\ *e-mail corresponding author: tkragh@bi.ku.dk
}

\begin{abstract}
The accumulation and degradation of carbohydrates (aldoses) were investigated during diatom blooms in two mesocosms. The effects of macrozooplankton were explored by addition of zooplankton to one mesocosm ( $+Z)$. Aldoses accumulated at a steady rate of $4.9 \mu \mathrm{MC} d^{-1}$ from day 9 in the mesocosm without zooplankton (-Z), while zooplankton induced an increased rate to $10.3 \mu \mathrm{MC} d^{-1}$. The surplus of $14 \mu \mathrm{M}$ dissolved combined carbohydrates (DCCHO) in the $+Z$ mesocosm after 22 days was caused by higher concentrations of arabinose, galactose and rhamnose. The increase was 50, 25 and 25\% respectively in the $+Z$ mesocosm, compared with the $-Z$ mesocosm. The introduction of zooplankton had a significant effect on the rate of biodegradation and the fraction of refractory aldoses. The accumulated aldoses became less labile and a larger fraction was refractory with the presence of zooplankton. During degradation the fraction of dissolved organic carbon (DOC) explained by aldoses decreased in the $-Z$ mesocosm while it increased with the presence of grazers. In the $+Z$ mesocosm, two new peaks appeared on the chromatograms and contributed about $4 \%$ to the total area of aldoses. It is hypothesised that these two peaks are an indicator of the presence of grazers.
\end{abstract}

Key words: algal bloom, zooplankton, grazing, carbohydrates

\section{INTRODUCTION}

Dissolved organic carbon (DOC) represents one of the largest active pools of organic carbon in the biosphere (Hedges 1992). A large fraction of the DOC remains chemically uncharacterized, but carbohydrates constitute the largest identified fraction of the DOC pool (Pakulski \& Benner 1994). Earlier studies report that carbohydrates can explain about $15 \%$ of the DOC pool (Burney et al. 1979; Harvey 1983; Senior \& Chevolot 1991), however, other studies have reported that carbohydrates make up to $33 \%$ of DOC larger than $1 \mathrm{kDa}$ (Burney et al. 1982; Benner et al. 1992). The carbohydrate pool is dynamic, and total carbohydrates (TCHO), can account for $47 \%$ of the total DOC consumption during summer (Burney et al. 1981).

One of the main sources of carbohydrates in many aquatic systems is phytoplankton, where biomass is typically made up of from 15 to $35 \%$ carbohydrate (Biddanda \& Benner 1997; Parsons et al. 1961). The production of dissolved compounds from phytoplankton is caused by direct exudation, predation and viral lysis. Direct exudation of DOC from phytoplankton is variable but most often varies within 5 to $20 \%$ of the primary production, and the loss rate seems to be related to the growth phase, nutrient supply and light. (Mague et al. 1980; Baines \& Pace 1991; Lancelot \& Billen 1985; Fogg 1983). When phytoplankton are growing carbohydrates are actively released in large amounts (Antia et al. 1963; Eberlein et al. 1983), and carbohydrates can contribute up to $70 \%$ of the DOC produced during blooms (Søndergaard et al. 2000). Predation is also an important factor in the production of DOC (Jumars et al.
1989; Lampert 1978). Although the actual amount lost during predation is not well known, between 4 to $20 \%$ of the carbon ingested by zooplankton is released into the dissolved phase and carbohydrates are one of the major constituents (Strom et al. 1997).

The measurement of carbohydrates is not straight forward, but it gives an insight into the mechanisms controlling the composition of DOM. The MBTH (3methyl-2-benzothiazolinone hydrazone hydrochloride) method is a bulk colorimetric method, which measures all major classes of carbohydrates including acidic sugars, amino sugars and neutral sugars. Chromatographic separation of neutral sugars (aldoses) provides a direct and sensitive measurement at the molecular level for an important subset of the entire carbohydrate pool. Aldoses have been reported to account for about $54 \%$ of bulk carbohydrates during bloom events (Biersmith \& Benner 1998). Knowing the sources and understanding the transformations and fate of carbohydrates at the molecular level can improve the understanding of the cycling of the photosynthetic products. An understanding of the molecular composition can also provide information about the origin and diagenetic state of the material, making aldoses useful as biomarkers (Cowie \& Hedges 1994).

In this study we report on the accumulation and degradation of dissolved combined neutral sugars (DCNS) in mesocosms with and without zooplankton grazers. Springwater with a low inert background of DCNS and DOC was used as growth media to ensure that any changes in the concentration and composition of the dissolved constituents were a result of either phytoplankton and smaller heterotrophs or grazing by larger zooplankton. 


\section{MATERIALS AND METHODS}

The mesocosm design and sampling were as described in Kragh and Søndergaard (2004). Briefly, two mesocosms (80 litres) containing spring water (Harrilds kildevand) were inoculated with $100 \mu \mathrm{m}$ pre-screened water from Lake Esrum Sø (approx. 20\% vol/vol) and kept in a $12 / 12 \mathrm{~L} / \mathrm{D}$ cycle. Nutrients were added as $\mathrm{KNO}_{3}(126 \mu \mathrm{M}), \mathrm{KH}_{2} \mathrm{PO}_{4}(8 \mu \mathrm{M})$ and $\mathrm{Na}_{2} \mathrm{SiO}_{3} \cdot 9 \mathrm{H}_{2} \mathrm{O}$ $(200 \mu \mathrm{M})$ to promote a phytoplankton bloom. After a phytoplankton bloom developed, a mixture of natural macrozooplankton $(>200 \mu \mathrm{m})$ was added to one of the mesocosms at natural density. The algal bloom was initially dominated by diatoms which later on were succeeded by green algae. The added mesozooplankton $>200 \mu \mathrm{m}$ were collected from 200 litres of water from Esrom Lake, and it was dominated by Daphnia and Cyclops species, but they were not quantified.

Samples for DOC, carbohydrates, chlorophyll- $a$, were taken daily, and samples for degradation experiments were taken 5 times during the experiment. The water for the degradation experiments were filtered (GF/F), and inoculated with a GF/C filtrate from the respective containers $(5 \% \mathrm{vol} / \mathrm{vol})$. Mineral nutrients

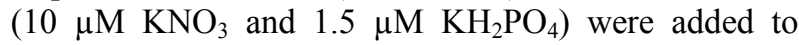
ensure carbon-limited bacterial growth. The degradation experiments were sampled with a decreasing intensity for a period of 230 days.

\section{ANALYTICAL METHODS}

Replicates of GF/F filtered water for dissolved carbohydrate analysis were sampled in pre-combusted glass vials and immediately frozen. Once the samples were defrosted $0.5 \mathrm{ml}$ were analysed directly for dissolved free neutral sugars (DFNS), while $3 \mathrm{ml}$ was hydrolyzed for measurement of dissolved combined neutral sugars (DCNS) as described in Borch \& Kirchman (1997) except that the samples were not neutralised with $\mathrm{CaCO}_{3}$. The particulate fraction was dried and subsequently hydrolysed in $3 \mathrm{ml}$ of Milli Q water and sulphuric acid for analysis of particulate carbohydrates. Samples were measured on a HPLC (Dionex DX500) microbore system with a PA10 column. The detection limits were $<10 \mathrm{nM}$ for individual species of the six aldoses separated. For concentrations reported here, total carbohydrates are expressed in carbon units using the carbon content of each hexose or pentose, whereas concentrations of individual aldoses are expressed in $\mathrm{nM}$ aldose.

\section{RESULTS}

\subsection{Carbohydrate concentrations during the bloom}

Most of the water $(80 \%)$ used for the mesocosms was spring water with initially low values for all measured variables. Increased concentrations of chlorophyll were measurable after 5 days and chlorophyll peaked at day 17 in both mesocosms with concentrations reaching
149 and $93 \mu \mathrm{g}^{-1}$ in the mesocosms without (-Z) and with zooplankton $(+Z)$, respectively (Fig. 1A).
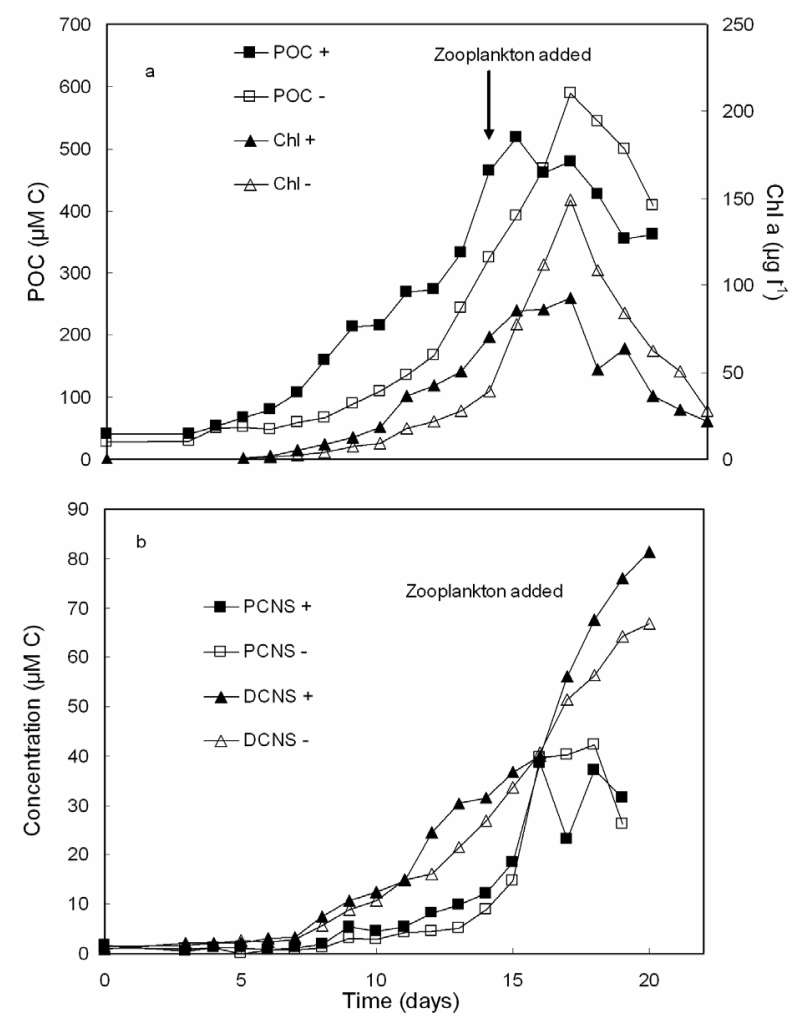

Fig. 1. Development of chlorophyll- $a$ and DCNS in the two mesocosms.

Following the peak, chlorophyll concentrations decreased rapidly in both mesocosms, and reached 22 and $28 \mu \mathrm{g}^{-1}$ at day 22. Nitrate and phosphate were below limits of detection for both mesocosms at day 15 and 13, respectively. Particulate organic carbon concentrations were initially between 30 and $40 \mu \mathrm{M} \mathrm{C}$ and no change was found during the first three days of the experiment. From day three to five, the mesocosms developed concurrently, but from then on a larger amount of POC accumulated in the mesocosm in which we later added zooplankton. When zooplankton was added at day 14 the grazing prevented further accumulation of POC and Chl- $a$ (Fig. 1A). The POC concentrations peaked at day 15 and 17, with 518 and $588 \mu \mathrm{M}$ $\mathrm{POC}$ in the $+\mathrm{Z}$ and $-\mathrm{Z}$ mesocosms, respectively. The decrease in POC and Chl- $a$ was a combination of nutrient exhaustion and grazing. Particulate combined neutral sugars (PCNS) did not accumulate in measurable concentrations during the first eight days of the experiment (Fig. 1B). From day 8 to day 15 PCNS accumulated with an almost even rate of $2 \mu \mathrm{M} \mathrm{C} \mathrm{d}^{-1}$ in both mesocosms. From day 15 to 16 the concentrations more than doubled from 15 and $18 \mu \mathrm{M}$ to 40 and $38 \mu \mathrm{M}$, in the $+\mathrm{Z}$ and $-\mathrm{Z}$ mesocosms, respectively. The concentrations in the following three days were fairly constant with one low value in the $+Z$ mesocosm. At day 19 
PCNS concentrations started to decrease in both mesocosms. During the first fourteen days of the experiment, only $4 \%$ of the POC could be explained by PCNS, however during the biomass peak PCNS explained up to $9 \%$ of the POC, which was the maximum for the whole experiment.

Dissolved combined carbohydrates started to accumulate above the initial low concentration of 3.3 and 2.7 $\mu \mathrm{M} \mathrm{C}$ from day 8 to 81.2 and $67.4 \mu \mathrm{M} \mathrm{C}$ at day 22 , in the two mesocosms with and without zooplankton, respectively (Fig. 1B). The concentrations increased throughout the experiment and thus did not follow the pattern of POC and Chl- $a$. The rate of accumulation was almost constant at $4.9 \mu \mathrm{M} \mathrm{C} \mathrm{d}^{-1}$ from day 9 to 22 in the $-\mathrm{Z}$ mesocosm.

The concentrations of DCNS in the mesocosm with added zooplankton increased with a rate of $4 \mu \mathrm{M} \mathrm{C} \mathrm{d}^{-1}$ from day 9 to day 18 . Concurrent with the collapse of the algal community on day 17 the rate of accumulation increased significantly to $10.3 \mu \mathrm{M} \mathrm{C} \mathrm{d}^{-1}(\mathrm{P}>0.05$, difference between regression lines). The concentrations of DCNS correlated positively with Chl- $a$ until the peak in Chl- $a$ at day 17. At this time DCNS continued to increase at a steady rate, while Chl- $a$ decreased. Even though the phytoplankton biomass was lower because of the grazing, more DCNS accumulated in the $+\mathrm{Z}$ treatment. At the end of the experiment most carbohydrates were found in the dissolved phase (Fig. 1B) and concentrations of DCNS were 2 fold higher than PCNS. Dissolved free carbohydrates were not detectable $(<10 \mathrm{nM})$ at any time during the experiment in either mesocosm.

The aldose yield (i.e. the carbohydrate content of total DOC) increased equally during the first 14 days from approximately $14 \%$ to $25 \%$ (Fig. 2 ) in both mesocosms. Without zooplankton the aldose yield remained constant at $23 \%$ during the peak and the decline even though the total DCNS concentration increased 4-fold (from 16 to $66 \mu \mathrm{M}$ C). In the mesocosm with zooplankton, the yield increased from 23 to $34 \%$ from day 14 to 22 .

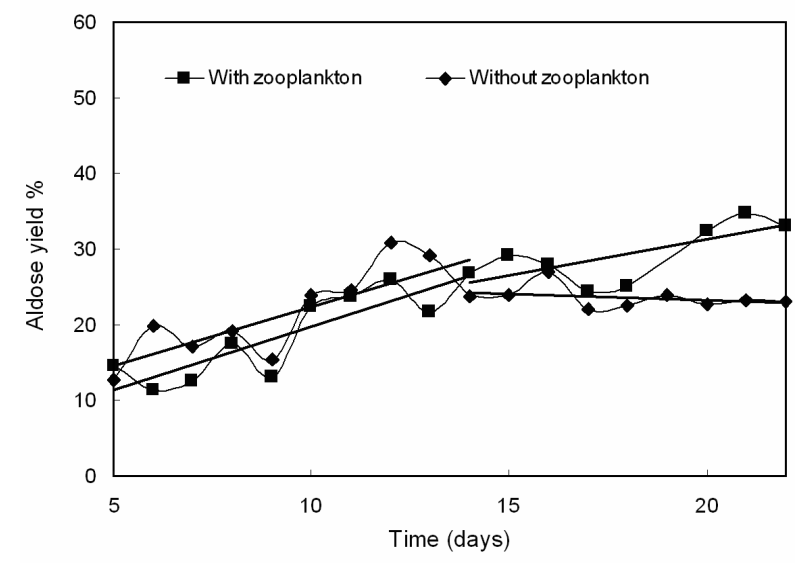

Fig. 2. The aldose yield throughout the experiment. Also shown are regression lines in the period before and after addition of zooplankton on day 14.
No major differences in the molecular composition of aldoses were found between the $+\mathrm{Z}$ and the $-\mathrm{Z}$ mesocosms until day 17 (Fig. 3). The results are very variable during the first days of the experiments because the concentrations of some sugars were at or below the detection limit. Apparently, the zooplankton had no effect on the molecular composition between day 14 and 17. Arabinose concentrations remained low during this period and only reached about $150 \mathrm{nM}$. The concentration of fucose, rhamnose and glucose started to increase at day 9, and at day 17 the concentrations were between 875 and $945 \mathrm{nM}$. Mannose and galactose concentrations increased to about 1250 and $1750 \mathrm{nM}$, respectively. From day 17 until day 20 differences at the molecular level developed between the $+Z$ and the $-Z$ mesocosms. The surplus of DCNS in $+Z$ mesocosm was caused by higher concentrations of arabinose, galactose and rhamnose. No distinct differences were found between glucose, fucose and mannose in the two mesocosms.

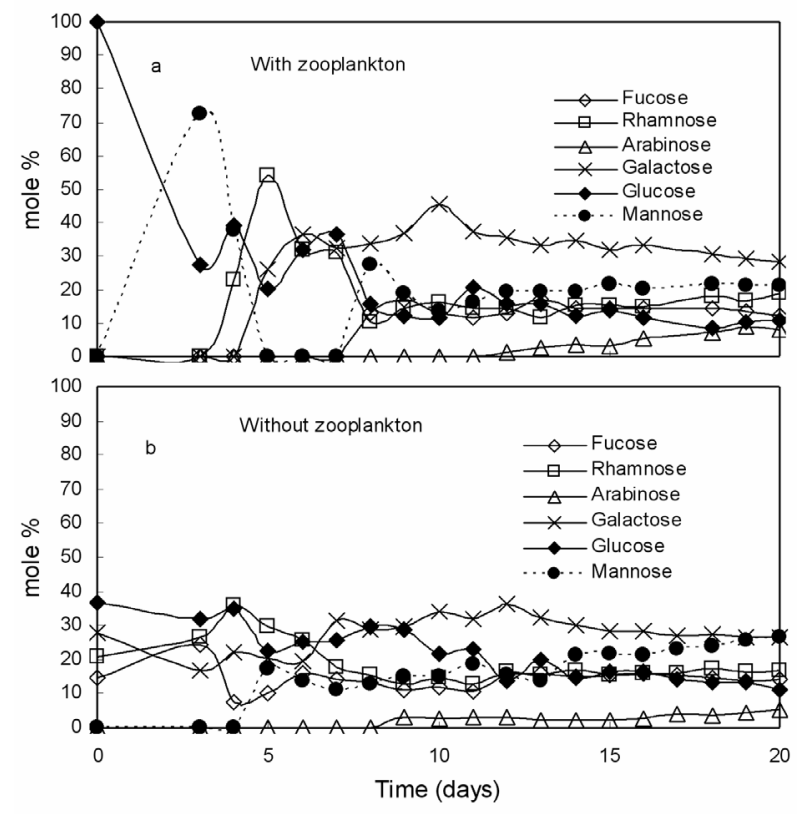

Fig. 3. Mole percent of the measured aldoses.

\subsection{Carbohydrate dynamics during decomposition}

A prerequisite for describing biodegradation of newly accumulated aldoses is that the observed background levels are either recalcitrant or non-existent. In this experiment the concentration of aldoses started below the detection limit and accumulated aldoses could accordingly be regarded as newly produced. The degradation experiments from the two mesocosms at day 5 and 12 can be regarded as duplicates, since macrozooplankton was first added at day 14. The DCNS produced during the first 14 days of the experiments exhibited similar patterns in degradation. All of the accumulated DCNS was degraded within 100 to 150 days (Fig. 4). 

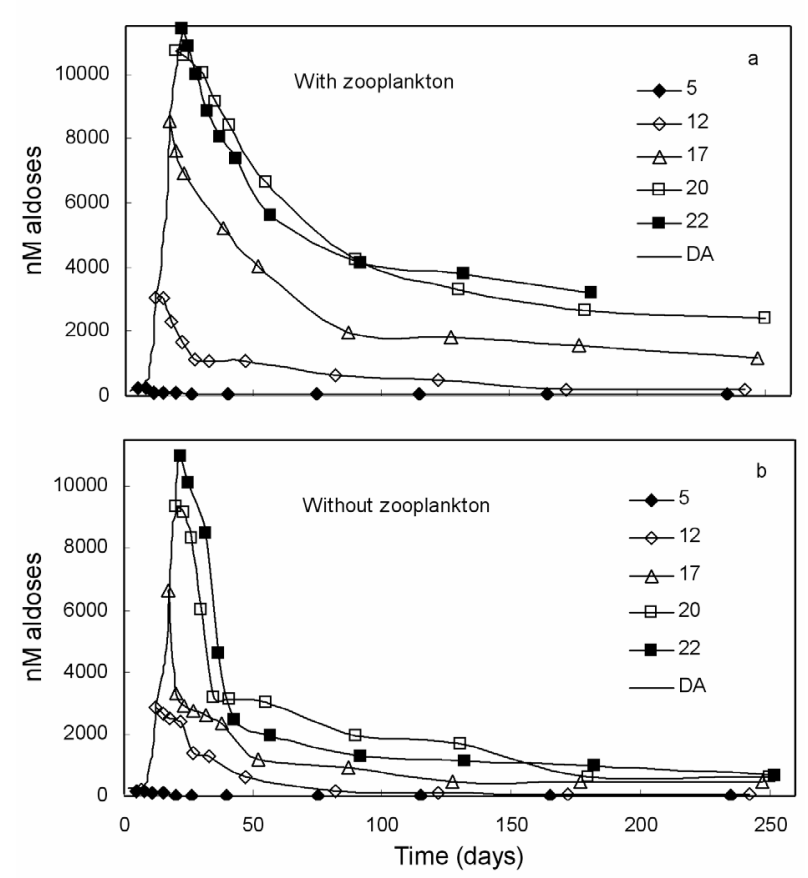

Fig. 4. Degradation of DCNS sampled 5 times during the experiment. Also shown is the daily accumulation (DA) during the 22 days the algae were in the light - dark cycle.

The degradation patterns changed after the addition of zooplankton. The DCNS in the $+Z$ mesocosm became less labile and the refractory fraction increased during the course of the experiment. With the presence of zooplankton about 40 to $50 \%$ of the accumulated DCNS were degraded after 35 days, while 70 to $80 \%$ of the DCNS from the $-\mathrm{Z}$ were removed. Between 160 and 250 days of degradation we could not detect any decrease, and the remaining fraction was defined as recalcitrant. The fraction of recalcitrant DCNS in the mesocosm with zooplankton increased during the experiment. In the $+\mathrm{Z}$ mesocosm 14, 22 and $28 \%$ of the accumulated DCNS on day 17, 20 and 22, was recalcitrant, whereas in the $-\mathrm{Z}$ mesocosm DCNS remained very low (Fig. 4).

The changes in composition of the aldoses during decomposition of samples from day 22 are shown in figure 5. With the presence of zooplankton the mol percentage remained stable for all aldoses except glucose and fucose. Glucose increased significantly $(\mathrm{P}>0.05)$ from 10 to $22 \%$ of the total aldoses, and fucose decreased significantly $(\mathrm{P}>0.05)$ from 15 to $6 \%$. The composition of aldoses in the samples without zooplankton changed rapidly within the first 21 days of decomposition. Fucose and rhamnose made up $17 \%$ and $7 \%$ of the aldoses at day 0 and both of them decreased below the detection limits at day 21 . At day 0 , arabinose was $9 \%$ and was no longer measurable at day 160 . All decreases were significant $(\mathrm{P}>0.05)$. With the decrease of fructose, rhamnose and arabinose, the relative com- bination of glucose and galactose increased significantly ( $\mathrm{P}>0.05$ ) from $11 \%$ and $23 \%$ at day 0 to $32 \%$ and $43 \%$ at day 230 , respectively.
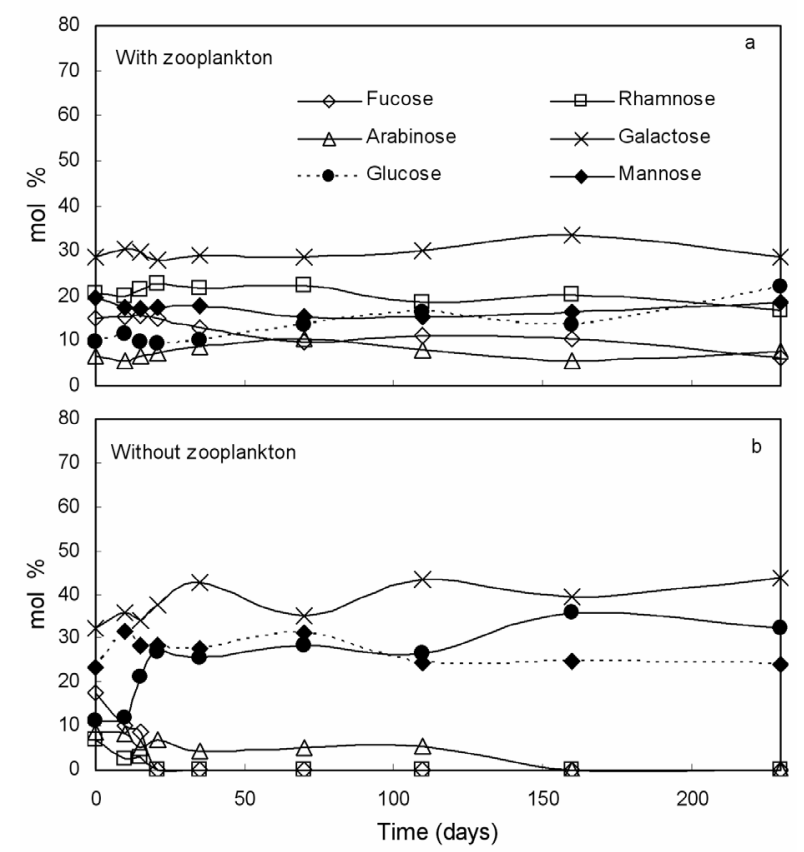

Fig. 5. Mole percent of the measured aldoses during the degradation experiment from day \# 22.

The relative percentage of DOC explained by DCNS was similar in the two mesocosms in samples from day 12 (Tab. 1). Values from day 5 are not shown because the accumulation of DOC and aldoses were very small. DCNS accounted for 33 to $24 \%$ of DOC in the samples collected at day 17, 20 and 22, and there were no differences between $+Z$ and $-Z$ mesocosms. After 230 days of decomposition DCNS was between 51 to $64 \%$ of DOC in the mesocosm with zooplankton, while only 8.5 to $11.2 \%$ of DOC could be explained by DCNS in the $-Z$ mesocosm (Tab. 1).

Tab. 1. The relative percentage of DCCHO compared to DOC in experiments plus and minus zooplankton.

\begin{tabular}{|c|c|c|c|c|c|}
\hline & & \multicolumn{4}{|c|}{ Decomposition day \# } \\
\hline & & 12 & 17 & 20 & 22 \\
\hline \multirow{2}{*}{$+\mathrm{Z}$} & day 0 & $31.4 \%$ & $31.9 \%$ & $29.6 \%$ & $32.9 \%$ \\
\hline & day 230 & $6.4 \%$ & $64.2 \%$ & $53.9 \%$ & $50.9 \%$ \\
\hline \multirow[b]{2}{*}{$-Z$} & day 0 & $31.8 \%$ & $28.4 \%$ & $25.7 \%$ & $22.8 \%$ \\
\hline & day 230 & $5.3 \%$ & $10.0 \%$ & $11.2 \%$ & $8.5 \%$ \\
\hline
\end{tabular}

\subsection{Formation of unidentified peaks}

After zooplankton was added to one mesocosm two additional peaks occurred on the chromatogram with retention times of 6.7 and 7.3 minutes (Fig 6). These two peaks were not present before the addition of zooplankton and never appeared in the mesocosm without zooplankton. The area represented by these two peaks 
makes up about $4 \%$ of the total peak area. The two compounds detected are dissolved in the water, and were not detected when particulate material was analysed. In another but similar experiment the same two peaks appeared only in mesocosms with zooplankton (data not shown). The two peaks are not of zooplankton origin because they do not appear in extracts from the hydrolysed zooplankton.

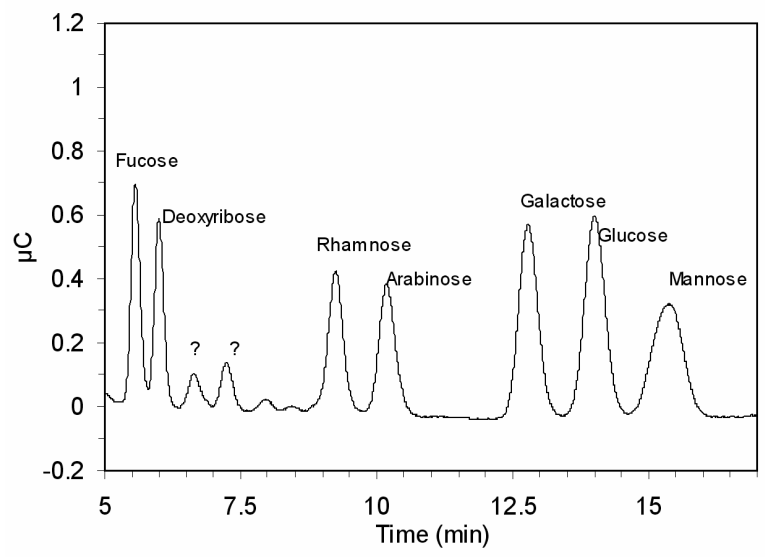

Fig. 6. Chromatograms from the mesocosm with zooplankton. Sample collected at day \# 22. Unclassified peaks are marked by a question mark (?).

\section{DISCUSSION}

The production and consumption of carbohydrates during and after a diatom bloom event was measured in two mesocosms, one with macrozooplankton $(+Z)$ and one without $(-Z)$. We used commercial spring water with a low and inert background as the medium for the mesocosms. This ensured low initial concentrations of carbohydrates and DOC, see Kragh \& Søndergaard (2004) making changes in accumulation and degradation patterns easy to detect. A high background concentration of the compounds of interest and an unknown history of degradability may obscure small changes due to biological activity.

Neutral sugars constituted only a minor part of the POC during the experiment, contrary to many other published findings where carbohydrates may constitute much higher proportion of the cells (e.g. Biersmith \& Benner 1998). The mesocosms in this study were on a $12 / 12$ hour light cycle, and sampled in the morning less than 1 hour after light had been switched on and production started. Therefore, it is quite possible that much of the stored carbohydrates were either respired or used for biosynthesis during the preceding 12 hours in the dark. Also, it is noteworthy that POC and Chl- $a$ values did not track each other, especially in the later part of the experiment. This just emphasizes the variation in $\mathrm{C}: \mathrm{Chl}$ ratios, which varied between 50 and 100 throughout the experiment with the lower value just before Chl- $a$ peaked (data not shown).
Accumulation of carbohydrates during bloom events and growth of phytoplankton has been observed in several studies (Biersmith \& Benner 1998; Ittekkot et al. 1981; Meon \& Kirchman 2001). However, our findings contrast with the generally accepted paradigm that phytoplankton, and especially diatoms, excrete large amounts of carbohydrates during nutrient limitation. Although the aldose yield increased, no dramatic decoupling between production and decomposition were found during senescence. Aldose yields of $20 \%$ have been found in a culture experiment where all DOC was newly produced (Biersmith \& Benner 1998). At least our results show that diatoms do not excrete neutral sugars to any larger extend than other organic compounds. We may hypothesize that if the phytoplankton indeed excreted carbohydrates in our experiment they may have been charged molecules such as acidic sugars, which are removed during the sample cleanup process used here.

Grazer induced release of DOC has been shown to range from 3 to $17 \%$ of ingested carbon for Daphnia pulex feeding on various algae (Lampert 1978). A major fraction of the released carbon will be in the form of carbohydrates, as carbohydrates typically constitute 15 to $35 \%$ of phytoplankton cell dry weight (Biddanda \& Benner 1997). Earlier studies indicated that zooplankton grazing has been associated with carbohydrate peaks (Burney et al. 1979). Carbohydrates were therefore expected to accumulate, unless all of the released carbohydrates were labile over the entire experiment. Zooplankton caused an increased accumulation of aldoses of $14 \mu \mathrm{M}$, and bacterial production increased by a factor of 2.6 (data shown in Kragh \& Sondergaard 2004). This result supports the idea that feeding zooplankton releases significant amounts of DOC and that the labile part of this causes bacterial production to increase, while the semi-labile and recalcitrant fractions accumulate.

The aldose compositions in the two mesocosms were not very different from the composition found in the upper layer of the oceans (McCarthy et al. 1996). Mole percentages of mannose and galactose were slightly lower in the ocean, while fucose and glucose were slightly higher. The molecular composition of the aldoses started to differentiate in the two mesocosms at day 17 concomitant with addition of the zooplankton. This alteration in composition of aldoses could indicate that a pool consisting of a different polymeric carbohydrate is produced when zooplankton is present. The results from the decomposition experiments also revealed a difference in lability between the treatments.

The aldoses, in the samples collected day \# 17, 20 and 22 from the mesocosm without zooplankton had a higher initial rate of decomposition and the fraction of recalcitrant aldoses was lower. As the presence of macrozooplankton was the only factor separating the two mesocosms, the most likely explanation is that the 
difference should be linked to their presence. We put forward three non-mutually exclusive mechanistic explanations (1): Direct production of polymeric carbohydrates with semi-labile and recalcitrant characteristics by the zooplankton could be one plausible explanation. This could happen through leaking of colloidal material from faecal pellets. (2) Sloppy feeding and thereby release of cell content, rather than the facultative excretion that the phytoplankton exerted. (3) The grazing pressure on the algae could induce them to alter the composition of the produced carbohydrates, which might explain the change from mainly labile to a mixture of labile, semi-labile and recalcitrant polymeric carbohydrates.

It has been suggested in the literature that single aldoses can be used as indicators of freshness of organic matter. A higher aldose yield indicates fresher and less degraded material (Amon et al. 2001; Skoog \& Benner 1997). Depletion of glucose has been found to be the strongest single aldose in determining the age of organic matter (Hernes et al. 1996). This observation is not supported by the present study, where the mole percent of glucose increased significantly in both mesocosms during 230 days of degradation. The results observed by Meon \& Kirchmann (2001) in a study somewhat comparable to the present, support the idea that the strict use of a glucose index could lead to erroneous conclusions. Instead of using single aldoses as indicators of diagenetic state the total aldose yield has been suggested as a more robust indicator. Results from the $-\mathrm{Z}$ mesocosm match well with this idea, as aldose yields were between 23 and 28 mole \% at day 0 and after 230 days of degradation decreased to 8 and 11 mole $\%$. The total aldose yield could not be used to describe the age of the organic matter in the mesocosm with zooplankton present, because the fraction of the polymeric carbohydrates produced were recalcitrant and this is the natural situation. This led to an increase in the mole percent of aldoses with the age of the organic matter. The decomposition experiment with zooplankton at day 17 yielded a mole $\%$ of 64 at day 230 and the experiment at day 22 yielded a mole \% of 51 at day 230 .

With the addition of zooplankton two unclassified peaks appeared on the chromatogram after 6.7 and 7.3 minutes. The area of these two peaks was equivalent to $4 \%$ of the total area of aldoses. The importance of these peaks was relatively higher in the particulate produced fraction in a mesocosm bloom experiment performed in the spring of 2000 (Kragh et al., unpublished) where they represented up to $7 \%$ of the area. The origin of these two peaks is unknown. The explanation for these peaks does not lie within the particulate fraction of DOM as the peaks were not present in the particulate measurements when zooplankton was absent. It is not clear whether they are produced directly by zooplankton, or whether zooplankton induce their production in algae. During decomposition the signal was traceable for 110 days, which indicates that the substances are semi-labile. The mesocosm experiment from spring 2000 (Kragh et al., unpublished) showed the same pattern of degradation, which could indicate that this is not a random coincidence. The relative area of the peaks seems to be dependent upon grazing, which makes them suitable as biomarkers of grazing pressure. The possibility to use these peaks as biomarkers to indicate recent grazer dominance should be explored in the future. In conclusion: the presence of macrozooplankton affected the dynamic and production of DCNS during a freshwater phytoplankton bloom, both quantitatively and qualitatively.

\section{ACKNOWLEDGMENTS}

We thank Anne Jacobsen for expert technical assistance. This work was supported by the Danish Natural Science Research Council grant \# 9901735.

\section{REFERENCES}

Amon, R.M.W., H.P. Fitznar \& R. Benner. 2001. Linkages among the bioreactivity, chemical composition, and diagenetic state of marine dissolved organic matter. Limnol. Oceanogr., 46: 287-297.

Antia, N.J., C.D. Mcallister, T.R. Parsons, K. Stephens \& J.D.H. Strickland. 1963. Further measurements of primary production using a large-volume plastic sphere. Limnol. Oceanogr., 8: 166-183.

Baines, S.B. \& M.L. Pace. 1991. The production of dissolved organic-matter by phytoplankton and its importance to bacteria - patterns across marine and fresh- water systems. Limnol. Oceanogr., 36: 1078-1090.

Benner, R., J.D. Pakulski, M. McCarthy, J.I. Hedges \& P.G. Hatcher. 1992. Bulk chemical characteristics of dissolved organic-matter in the ocean. Science, 255: 1561-1564.

Biddanda, B. \& R. Benner. 1997. Carbon, nitrogen, and carbohydrate fluxes during the production of particulate and dissolved organic matter by marine phytoplankton. Limnol. Oceanogr., 42: 506-518.

Biersmith, A. \& R. Benner. 1998. Carbohydrates in phytoplankton and freshly produced dissolved organic matter. Mar. Chem., 63: 131-144.

Borch, N.H. \& D.L. Kirchmann. 1997. Concentration and composition of dissolved combined neutral sugars (polysaccharides) in seawater determined by HPLC-PAD. Mar. Chem., 57: 85-95.

Burney, C.M., P.G. Davis, K.M. Johnson \& J.M. Sieburth. 1982. Diel relationships of microbial trophic groups and insitu dissolved carbohydrate dynamics in the caribbean sea. Mar. Biol., 67: 311-322.

Burney, C.M., K.M. Johnson, D.M. Lavoie \& J.M. Sieburth. 1979. Dissolved carbohydrate and microbial atp in the north-atlantic - concentrations and interactions. Deep-Sea Res. Part A Oceanographic Research Papers, 26: 12671290.

Burney, C.M., K.M. Johnson \& J.M. Sieburth. 1981. Diel flux of dissolved carbohydrate in a salt-marsh and a simulated estuarine ecosystem. Mar. Biol., 63: 175-187.

Cowie, G.L. \& J.I. Hedges. 1994. Biochemical indicators of diagenetic alteration in natural organic-matter mixtures. Nature, 369: 304-307.

Eberlein, K., U.H. Brockmann, K.D. Hammer, G. Kattner \& M. Laake. 1983. Total dissolved carbohydrates in an enclosure experiment with unialgal Skeletonema-Costatum culture. Mar. Ecol. Progress Series, 14: 45-58. 
Fogg, G.E. 1983. The ecological significance of extracellular products of phytoplankton photosynthesis. Botanica Marina, 26: 3-14.

Harvey, G.R. 1983. Dissolved carbohydrates in the new-york bight and the variability of marine organic-matter. Mar. Chem., 12: 333-339.

Hedges, J.I. 1992. Global biogeochemical cycles - progress and problems. Mar. Chem., 39: 67-93.

Hernes, P.J., J.I. Hedges, M.L. Peterson, S.G. Wakeham \& C. Lee. 1996. Neutral carbohydrate geochemistry of particulate material in the central equatorial Pacific. Deep-Sea Res. Part II Topical Studies in Oceanography, 43: 11811204.

Ittekkot, V., O. Brockman, W. Michaelis \& E.T. Degens. 1981. Dissolved free and combined carbohydrates during a phytoplankton bloom in the Northern North Sea. Mar. Ecol. Progress Series, 4: 299-305.

Jumars, P.A., D.L. Penry, J.A. Baross, M.J. Perry \& B.W Frost. 1989. Closing the microbial loop - dissolved carbon pathway to heterotrophic bacteria from incomplete ingestion, digestion and absorption in animals. Deep-Sea Res. Part A Oceanographic Research Papers, 36: 483-495.

Kragh, T. \& M. Søndergaard. 2004. Production and bioavailability of autocthonous DOC: Effects of zooplankton. Aquatic Microbial Ecology, 36: 61-72.

Lampert, W. 1978. Release of dissolved organic carbon by grazing zooplankton. Limnol. Oceanogr., 23: 831-834.

Lancelot, C. \& G. Billen. 1985. Carbon-nitrogen relationships in nutrient metabolism of coastal marine ecosystems. $A d v$. aquat. Microbiol., 3: 264-321.

Received: February 2006

Accepted: April 2006
Mague, T.H., E. Friberg, D.J. Hughes \& I. Morris. 1980. Extracellular release of carbon by marine phytoplankton; a physiological approach. Limnol. Oceanogr., 25: 262-279.

McCarthy, M., J. Hedges \& R. Benner. 1996. Major biochemical composition of dissolved high molecular weight organic matter in seawater. Mar. Chem., 55: 281-297.

Meon, B. \& D.L. Kirchman. 2001. Dynamics and molecular composition of dissolved organic material during experimental phytoplankton blooms. Mar. Chem., 75: 185-199.

Pakulski, J.D. \& R. Benner. 1994. Abundance and distribution of carbohydrates in the ocean. Limnol. Oceanogr., 39: 930-940.

Parsons, T.R., K. Stephens \& J.D.H. Strickland. 1961. On the chemical composition of 11 species of marine phytoplankters. J. Fish. Res. Bd Canada, 18: 1001-1016.

Senior, W. \& L. Chevolot. 1991. Studies of dissolved carbohydrates (or carbohydrate-like substances) in an estuarine environment. Mar. Chem., 32: 19-35.

Skoog, A. \& R. Benner. 1997. Aldoses in various size fractions of marine organic matter: Implications for carbon cycling. Limnol. Oceanogr., 42: 1803-1813.

Søndergaard, M., P.J.le.B. Williams, G. Cauwet, B. Riemann, C. Robinson, S. Terzic, E.M.S. Woodward \& J. Worm. 2000. Net accumulation and flux of dissolved organic carbon and dissolved organic nitrogen in marine plankton communities. Limnol. Oceanogr., 45: 1097-1111.

Strom, S.L., R. Benner, S. Ziegler \& M.J. Dagg. 1997. Planktonic grazers are a potentially important source of marine dissolved organic carbon. Limnol. Oceanogr., 42: 13641374. 